\title{
QUALIDADE NA EDUCAÇÃO DA PRIMEIRA INFÂNCIA: AS POLÍTICAS PÚBLICAS E AS ESCOLAS MUNICIPAIS DE EDUCAÇÃO INFANTIL DO MUNICÍPIO DE SANTA MARIA/RS \\ http://dx.doi.org/10.5902/2318133824561
}

\author{
Andressa Wiedenhoft Marafiga \\ Colégio Marco Polo, Brasil.
}

\author{
Taciana Camera Segat \\ Universidade Federal de Santa Maria, Brasil.
}

\begin{abstract}
Resumo
Toda criança tem o direito a uma instituição escolar infantil de qualidade, que zele pelo seu bemestar, potencializando seu desenvolvimento ao máximo. A partir desse entendimento é que se apresenta este artigo com a seguinte problemática: de que maneira as políticas que tratam de qualidade na educação infantil são compreendidas e implantadas em duas escolas para a infância? A coleta de dados foi feita por questionários entregues para professores e equipe diretiva de duas escolas municipais de educação infantil - Emeis - da cidade de Santa Maria/RS. Ao longo deste artigo será discorrido sobre políticas públicas e critérios minimamente básicos para se ter qualidade nas instituições de primeira infância.

Palavras-chave: educação infantil, políticas públicas, gestão escolar, qualidade.
\end{abstract}

\section{QUALITY IN EDUCATION IN THE EARLY CHILDHOOD: ABOUT THE PUBLIC POLICIES AND THE EMEIS OF THE MUNICIPALITY OF SANTA MARIA - RS}

\begin{abstract}
Every child has the right to early childhood school institution of quality, which ensures his wellbeing, strengthening its development to the maximum. From this understanding is that this paper presents itself, with the following problematic: In which way the policies that treat of quality in Early Childhood Education are being comprehended and implemented in two schools for the early childhood? Thus, the data collection was the delivery of questionnaires for two municipal school of early childhood education - Emeis - of Santa Maria city/RS. These were directed one to the teachers and the other to the directive team. Throughout this paper, it will be discoursed about: public policies and criteria minimally basic for having quality in the institutions of early childhood. Key-words: early childhood education, public policies, school management, quality.
\end{abstract}




\section{Introdução}

$\mathrm{M}$ uitas inquietações referentes ao nível da educação infantil. Frente a isso refletimos sobre o que é necessário para que se tenha uma educação infantil de qualidade. De que qualidade está se falando? Muitos eram e continuam sendo nossos questionamentos, afinal eles nunca se encerram, mas continuam permeando nossa prática diária para melhorar nosso trabalho. Diante disso elencamos como problemática a ser pesquisada na Especialização em Gestão Educacional na Universidade Federal de Santa Maria (UFSM) a seguinte: se que maneira as políticas que tratam de qualidade na Educação Infantil vem sendo compreendidas e implementadas em duas escolas para a infância no município de Santa Maria - RS?

Como metodologia da pesquisa optou-se por questionários: um questionário para a equipe diretiva da escola, em que as seis primeiras questões eram referentes ao nome fictício da escola, data de fundação, gênero dos sujeitos da equipe escolar, formação, tempo de carreira e idade. O outro questionário era direcionado para os professores da educação infantil, sendo esses divididos para professores que atuam com crianças de 0 a 3 anos e outro para professores de crianças de 4 a 6 anos. Contou-se com a participação de 10 docentes, pois alguns questionários não se obteve retorno. Foram pesquisadas duas Emeis, designadas de Escola Rosa e outra Escola Amarela.

Observou-se nos questionários algumas informações: como ambas as Emeis não contam com vice-direção, apenas direção e supervisão/orientação. Também notou-se que todas as pessoas envolvidas possuem graduação em Pedagogia, demonstrando o acesso à universidade, bem como, a especialização que todas possuem. Especialização em Gestão Escolar é a opção formativa da maioria, apenas uma não cursou. Demonstrando a continuação da formação, perpassando a graduação, como também uma experiência para quem atua na área da gestão. Há também uma mescla nas idades das pessoas que assumem a equipe diretiva. Percebeu-se, também, a predominância do sexo feminino na área da educação infantil, evidenciando que mesmo na atualidade com um espaço maior para discussões de gênero, ainda necessitamos explorar essa temática.

O referencial teórico envolveu os Parâmetros nacionais de qualidade para educação infantil, volume 1 e 2 (2006); Indicadores da qualidade na educação infantil (2009), Critérios para um atendimento em creche que respeite os direitos fundamentais das crianças (2009) e Diretrizes curriculares nacionais para educação infantil (2009).

\section{Políticas públicas: em busca da implantação da qualidade na primeira infância}

Para que se tenha um ambiente adequado é importante à discussão do termo qualidade. Esse demonstra múltiplas interpretações, pois, não é algo neutro, mas sim baseado em um conceito de crenças e valores. Assim, não pode ser algo sem movimento, parado, mas democrático, revisto e pensado inúmeras vezes, continuo e permanente, refletido e contextualizado de acordo com cada realidade de cada espaço social. 0 conceito de qualidade "diz respeito, principalmente, à definição por meio de especificação de critérios, de um padrão generalizável em contraposição ao qual um produto pode ser julgado com certeza" (Dahlberg; Moss; Pence, 2003, p. 127).

Qualidade refere-se a inúmeros princípios. Campos e Cruz (2011) destacam o debate sobre qualidade da educação, nas seguintes termos: 
A qualidade é um conceito socialmente construído, sujeito a constantes negociações; depende do contexto; baseia-se em direitos, necessidades, demandas, conhecimentos e possibilidades; a definição de critérios de qualidade está constantemente tensionada por essas diferentes perspectivas. (p. 15)

No nível da Educação Infantil o termo qualidade gera outro campo de atividade, como relatam Dahlberg; Moss; Pence (2003, p. 134): "O desenvolvimento de padrões e diretrizes de boa prática para várias formas de provisão de cuidados à primeira infância, que, embora não-estruturados como medidas ou método de avaliação, na verdade proporcionam definições de qualidade".

No que tange a educação infantil existem condições mínimas e objetivas para a garantia do respeito aos direitos das crianças, consequentemente, à garantia de um atendimento de qualidade. Neste sentido há algumas políticas pelas quais se busca uma melhor qualidade na educação infantil. A seguir apresentam-se algumas destas principais políticas.

Os Parâmetros nacionais de qualidade para a educação infantil, criados em 2006, tem a finalidade de definir parâmetros de qualidade de modo a estabelecer requisitos necessários para uma educação infantil que possibilite o desenvolvimento integral da criança até os cinco anos de idade, em seus aspectos físicos, psicológicos, intelectual e social. É um documento dividido em dois volumes. No primeiro volume realizam uma contextualização a partir dos seguintes eixos:

1) a concepção de criança e de pedagogia da Educação Infantil; 2) o debate sobre a qualidade da educação em geral e o debate específico no campo da educação da criança de 0 até 6 anos; 3) os resultados de pesquisas recentes; 4) a qualidade na perspectiva da legislação e da atuação dos órgãos oficiais do pais. (Brasil, 2006, p. 13)

No segundo volume são apresentadas três seções de discussão: Competências dos sistemas de ensino; Caracterização das instituições de educação infantil no Brasil; Parâmetros nacionais de qualidade para as instituições de educação infantil.

Os parâmetros permeiam por questões da organização pedagógica, as atribuições dos gestores, interações nas instituições até a infraestrutura. Todos os segmentos trazidos no documento, mesmo sendo apresentados de maneira separada, devem estar relacionados nas práticas das instituições para que assim se efetive a qualidade na educação infantil. Entendendo que para que essa qualidade seja alcançada, instituição, pais, comunidade, devem estar junto em prol dos mesmos objetivos.

Outro documento são Indicadores da Qualidade na Educação Infantil. O mesmo visa a traduzir e aprofundar os Parâmetros nacionais de qualidade, oferecendo um instrumento a mais no apoio ao trabalho das instituições da primeira infância. Apresenta uma seção intitulada Como utilizar os indicadores da qualidade na educação infantil, na qual é discorrido sobre diversos aspectos, como por exemplo, a maneira de se conduzir a avaliação, os materiais que são utilizados, sobre as faixas etárias, etc. É destacado que não existe uma forma única de se utilizar o documento, pois ele é flexível, podendo ser 
usado de acordo com a experiência de cada instituição. Também salienta-se a importância da mobilização da comunidade para participar da avaliação, pois quanto mais pessoas de diferentes segmentos se envolverem em busca da qualidade na Educação Infantil, maiores serão os ganhos para as crianças.

O documento apresenta sete dimensões fundamentais que devem ser consideradas na reflexão sobre a qualidade das instituições da primeira infância. Para avaliar essas dimensões, "foram propostos sinalizadores da qualidade de aspectos importantes da realidade da educação infantil: os indicadores" (Brasil, 2009, p. 15). As sete dimensões são: 1) Planejamento Institucional; 2) Multiplicidade de experiências e linguagens; 3) Interações; 4) Promoção da saúde; 5) Espaços, materiais e mobiliários; 6) Formação e condição de trabalho das professoras e demais profissionais e 7) Cooperação e troca com as famílias e participação na rede de proteção social. Os indicadores pretendem colaborar para que as instituições de educação infantil possam reconhecer seus pontos fortes e fracos e possam intervir de maneira a melhorar a qualidade de acordo com as necessidades apontadas nas avaliações.

Os Critérios para um atendimento em creche que respeite os direitos fundamentais das crianças tem sua primeira versão no ano de 1995 e a segunda versão em 2009. 0 documento expõe como objetivo central "atingir um patamar mínimo de qualidade que respeite a dignidade e os direitos básicos das crianças, nas instituições onde muitas delas vivem a maior parte de sua infância" (MEC, 2009, p. 7).

Este documento é composto de duas partes: a primeira intitulada Esta creche respeita a criança: critérios para a unidade creche, contém critérios relativos à organização e ao funcionamento interno das creches, às práticas concretas a quem atua diretamente com as crianças. Na segunda parte temos A política de creche respeita a criança - Critérios para políticas e programas de creche, com a explicitação dos critérios relativos à definição de diretrizes e normas políticas, programas e sistemas de financiamento de creches, tanto governamentais, quanto não governamentais.

Em 2009 surgem as Diretrizes curriculares nacionais para educação infantil como reguladora das políticas, tendo como objetivo orientar as políticas públicas e a elaboração, planejamento, execução e avaliação de propostas pedagógicas e curriculares de educação infantil - resolução n. 5, de 17 de dezembro de 2009. Como definição de criança tem-se:

Sujeito histórico e de direitos que, nas interações relações e práticas cotidianas que vivencia, constrói sua identidade pessoa e coletiva, brinca, imagina, fantasia, deseja, aprende, observa, experimenta, narra, questiona e constrói sentidos sobre a natureza e a sociedade, produzindo cultura. (Brasil, 2010, p. 12)

Que direitos seriam esses? Onde encontramos explicitamente esses direitos? Direito a brincadeira? Mas em que momento essa brincadeira ocorreria? Direito a um espaço adequado? Ao amor? A escuta sensível ao que dizem as crianças? Ou o direito apenas ao acesso na Educação Infantil? Ou a tudo isso que aqui se refere?

As políticas assim pressupõem ações governamentais, implantadas por meio de documentos oficiais. As mesmas vêm prontas do governo para o âmbito escolar, sem a participação de quem estão diariamente nas escolas, professores, diretores, supervisores, 
crianças, etc. Entretanto, mesmo sem essa participação direta, é na escola que essas políticas se efetivam, cabendo aos sujeitos envolvidos na escola a compreensão e entendimentos destas políticas.

\section{Políticas familiares às professoras}

Foi a partir da década de 1980 que a educação infantil começou a se expandir: creches e pré-escolas começaram a ser vistas como um direito da criança e não mais da família. Em 1988, com a Constituição, os direitos são específicos das crianças de todas as camadas sociais. O texto definiu como dever do Estado a educação básica obrigatória e gratuita dos 4 anos aos 17 anos de idade (art. 208, inciso I), bem como o "atendimento em creche e pré-escola às crianças de zero a seis anos de idade" (art. 208, inciso IV). Já em 1996, com a LDB, evidenciou-se a importância da educação infantil e considerou-se a mesma como a primeira etapa da educação básica. A educação infantil ganhou maior visibilidade e reconhecimento, tendo seu campo de atuação definido a partir das necessidades específicas das crianças desta faixa etária.

Inicia-se um processo de discussão e reflexão tendo a criança como foco e sujeito de direitos. Neste contexto o MEC organizou seminários com intuito de definir políticas para a educação infantil. Surgiram destes encontros diversos documentos, como os já citados neste trabalho: Parâmetros Nacionais de Qualidade para Educação Infantil, volume 1 e 2 (2006); Indicadores da Qualidade na Educação Infantil (2009), Critérios para um atendimento em creche que respeite os direitos fundamentais das crianças (2009), entre outros.

Diante disso, quais são as políticas mais lembradas pelas professoras? Foram citadas: PNQEI (2006) - Parâmetros Nacionais de Qualidade para a Educação Infantil, por duas professoras; os Indicadores (2009) - Indicadores da Qualidade na Educação Infantil, também por duas professoras; DCNEI (2010) - Diretrizes Curriculares Nacionais para Educação Infantil, foi lembrada por três docentes; a LDB (1996) - Lei de Diretrizes e Bases, foi a mais citada, totalizando quatro professoras; o PNE (2014) - Plano Nacional de Educação, por três docentes; os PCNs (1997) - Parâmetros Curriculares Nacionais, por também três docentes; o RCNEI (1998) - Referencial Curricular Nacional para Educação Infantil, por duas professoras; e a PNEI (2006) - Política Nacional de Educação Infantil pelos direitos das crianças de zero a seis anos à Educação, por apenas uma docente.

Assim, as professoras descreveram quais e quantas políticas mais se familiarizavam: na escola Rosa todas responderam. Na Amarela duas docentes não responderam à questão e outra professora destacou: "Materiais de apoio pedagógico disponibilizado pela escola" (Júlia), mas não continuou a descrição dizendo quais seriam. Destaca-se a diferença de uma gestão atuante na escola, pois quando todos os envolvidos têm entendimento sobre seus papéis na dinâmica escolar, isso é um fator para determinar a qualidade da instituição. Na Emei Rosa todas se comprometeram em responder a referida questão. Provavelmente isso se deve a figura central da diretora em promover situações para o ganho da qualidade, como também, imprimi marcas nas relações interpessoais no âmbito escolar. 
Como descrito acima a política mais lembrada - quatro docentes -, foi a Lei de Diretrizes Bases (LDB/ no 9.394/96), talvez por essa ser base de todas as políticas que vem após. Chama atenção os PCNs (1997) e os Referenciais (1998) ainda serem lembrados diante de tantas outras políticas voltadas ao nível da educação infantil, como também aos anos iniciais. Apresentam-se como um dado interessante que as professoras que citaram esses dois documentos são as que têm um tempo de carreira maior. Já duas docentes com menos tempo citaram os documentos mais recentes e específicos ao nível da educação infantil, como os Parâmetros de qualidade para a educação infantil e os Indicadores da qualidade. Uma destas docentes possui especialização em Docência na Educação Infantil. Seria muito interessante pensar em formações a partir destes diferentes sujeitos atuantes na escola, pois é no âmbito escolar que se apresenta as maiores possibilidades para formações e para a realização do conhecimento compartilhado que se

refere às trocas entre pares/docentes e o aprofundamento sobre temas trabalhados coletivamente, implicando na autonomia dos professores, permitindo-Ihes, a partir da reestruturação pessoal dos seus esquemas de conhecimento, resolver diferentes situações didático-pedagógicas e profissionais. O compartilhar de ajuda ou estímulo envolve a atividade colaborativa, favorecendo o avanço do professor com relação ao seu desenvolvimento intelectual. (Bolzan, 2002, p. 380)

O conhecimento compartilhado entre os membros do grupo pode permitir aos envolvidos uma aprendizagem docente reflexiva, tendo em vista o desenvolvimento intelectual, do pensamento teórico do profissional. É válido salientar que o conhecimento compartilhado é colaborativo, tendo em vista a interdependência dos sujeitos envolvidos. De acordo com Bolzan (2009, p. 136), "os significados sociais das vozes vão sendo apropriados pelos indivíduos durante a conversação, sendo desvelados ao serem trazidos à luz pelo pensamento e expressos coletivamente".

Apenas a professora Violeta da Emei Rosa destacou uma política diferente, sendo a Política nacional de educação infantil pelo direito das crianças de zero a seis anos à educação. A mesma foi criada no ano de 2006, contêm diretrizes, objetivos, metas e estratégias para a área da educação infantil. Apresenta como objetivo o de propiciar o cumprimento do preceito constitucional da descentralização administrativa. Destaca-se que um dos documentos que nesta pesquisa está se referindo, Critérios para um atendimento em creches que respeite os direitos fundamentais das crianças, não foi citado por nenhuma das professoras pesquisadas.

No questionário referente à equipe diretiva, na questão "Você conhece o documento Critérios para um atendimento em creche que respeite os direitos fundamentais das crianças?" ambas Emeis relataram conhecer o documento. O mesmo está na escola, sendo disponibilizado pelo MEC ou pela Secretaria de Município da Educação. Porém, quando questionadas quais documentos são norteadores das práticas escolares o mesmo não aparece, nem na direção, nem na manifestação das docentes. Ao contrário dos outros dois documentos - Parâmetros nacionais de qualidade para a educação infantil e os Indicadores da qualidade na educação infantil - que apareceram nas respostas de algumas professoras. 
A escola Rosa cita os seguintes documentos como norteadores: Plano Nacional da Educação, LDB, Diretrizes curriculares para a educação infantil e Projeto políticopedagógico da escola.

A Emei Amarela cita apenas Projeto político-pedagógico. Notou-se que apenas um documento específico da educação infantil é citado, as Diretrizes, e apenas em uma Emei. Diante disso questiona-se se esses documentos dirigidos a este nível chegam às escolas? Supondo que os mesmos chegam, será que vêm sendo compreendido e internalizado pelas gestões escolares?

$\mathrm{Na}$ sequência, em uma questão perguntou-se como surgem as temáticas a serem trabalhadas com as crianças. Na escola Amarela a resposta foi: "Sugestão de professores e equipe diretiva". Na escola Rosa: "Planejamos".

Por que motivo não aparece nesta questão o foco na criança? No documento Indicadores da qualidade na educação infantil, na primeira dimensão, Planejamento institucional, há o indicador Proposta pedagógica consolidada, com a seguinte questão: "A proposta pedagógica foi elaborada e é periodicamente atualizada com a participação das professoras, demais profissionais e famílias, considerando os interesses das crianças"? (Brasil, 2009, p. 38). Também o indicador Planejamento, acompanhamento e avaliação, com a questão "Na prática de planejamento e avaliação, criam-se condições para que as crianças também possam manifestar suas opiniões"? (Brasil, 2009, p. 38).

Mas em que momento isso acontece? Como ocorre? E a partir de que interesse? Para que se tenha uma aprendizagem significativa o assunto a ser estudado deve vir do interesse da criança. É a turma em seu conjunto que definem as temáticas a serem trabalhadas em sala de aula, partindo de suas experiências, curiosidades e interesses. Hernández e Ventura (1998) destacam que isso não impede de que o professor também possa propor aqueles temas que consideram necessários.

É importante que o docente estabeleça um diálogo com as crianças, deixando que suas ideias surjam e assim as respeitando, consentindo que a imaginação, criatividade e seus conhecimentos sejam ditos. Segundo Weisz (2009) caso isso não aconteça não se conseguirá construir uma verdadeira situação de aprendizagem, pois não se permitiu que se crie um problema sobre o qual seja preciso pensar. Portanto, o professor não pode simplesmente assumir o lugar de quem já sabe, mas sim o lugar de aprendente e escolher junto da criança os caminhos a serem percorridos, fazendo com que essa se sinta com sua voz escutada e assim respeitada, como também, sinta prazer em aprender e estar na escola.

\section{Considerações finais}

Iniciamos estas considerações destacando que o objetivo não era fazer comparações entre as Emeis ou dizer o que está certo ou errado, pois essas palavras podem ser dúbias e de diferentes significações para cada sujeito. Todavia o que queríamo, era o de provocar algumas reflexões acerca das instituições de educação infantil e das políticas que tratam sobre qualidade para educação das crianças, com intuito de ajudar em possíveis melhorias nas Emeis. 
Tinham-se alguns objetivos para o trabalho, como o de identificar como estava sendo vivenciado, no âmbito escolar, as políticas que visam a implantar a qualidade no atendimento às crianças em Emeis de Santa Maria, assim como de que maneira os documentos subsidiam o entendimento da equipe diretiva e professores sobre qualidade na educação infantil.

Nesse sentido, mesmo que os documentos Parâmetros Nacionais de Qualidade para Educação Infantil, volume 1 e 2 (2006); Indicadores da Qualidade na Educação Infantil (2009), Critérios para um atendimento em creche que respeite os direitos fundamentais das crianças (2009) estejam disponibilizados nas Emeis, como respeitar a qualidade e os direitos fundamentais das crianças se os mesmos não estão sendo vivenciado no âmbito escolar? Não estamos querendo dizer que os documentos precisam ser levados em consideração em todos os seus aspectos, que são a salvação para tudo e todos. Mas, saibamos que os mesmos apresentam pontos importantes, como elencar parâmetros, indicadores e critérios minimamente necessários para o trabalho com crianças de Educação Infantil:

nenhuma escola pode ser melhor do que os profissionais que nela atuam. Nem o ensino pode ser democrático, isto é, de qualidade para todos, caso não se assente sobre padrões de qualidade e competências profissionais básicas que sustentem essa qualidade. A busca permanente pela qualidade e melhoria contínua da educação passa, pois, pela definição de padrões de desempenho e competências de diretores escolares, dentre outros, de modo a nortear e orientar o seu desenvolvimento. Este é um desafio que os sistemas, redes de ensino, escolas e profissionais enfrentam e passam a se constituir na ordem do dia das discussões sobre melhoria da qualidade do ensino. (Lück, 2009, p. 12)

Também se destaca que as reflexões, discussões e estudos se fizeram de grande contribuição para nós profissionalmente, afinal também somos professoras, seja de crianças da primeira infância, ou universitárias, e nos constituímos como tal a cada dia que passa com novas aprendizagens e descobertas.

\section{Referências}

BOLZAN, Doris. Pires. Vargas. Formação de professores: compartilhando e reconstruindo conhecimentos. Porto Alegre: Mediação, 2002.

BOLZAN, Doris. Pires. Vargas. Formação permanente e conhecimento pedagógico compartilhado: possibilidades na docência universitária. In: ISAIA, Silvia Maria de Aguiar; BOLZAN, Doris Pires Vargas; MACIEL, Adriana Moreira da Rocha. Pedagogia universitária: tecendo redes sobre a educação superior. Santa Maria: UFSM, 2009.

BRASIL. Constituição da República Federativa do Brasil de 1988. Disponível em $<$ http://www.planalto.gov.br/ccivil 03/constituicao/constituicao.htm>. Acesso em $28 \mathrm{dez}$. 2015.

BRASIL. Diretrizes Curriculares Nacionais para a Educação Infantil. Resolução № 05/CNE/CEB, Brasília, 2009.

BRASIL. Indicadores da qualidade na educação infantil. Brasília: MEC/SEB, 2009. 
BRASIL. Parâmetros nacionais de qualidade para a educação infantil. Brasília: MEC, 2006.

BRASIL. Ministério da Educação. Secretaria de Educação Básica. Parâmetros básicos de infra-estrutura para instituições de Educação Infantil. Brasília: MEC/SEB, 2006.

MINISTÉRIO DA EDUCAÇÃO. Brinquedos e brincadeiras de creches. Brasília: MEC, 2012.

CAMPOS, Maria. Malta; CRUZ, Silvia. Helena. Vieira. Consulta sobre qualidade da educação infantil: o que pensam e querem os sujeitos deste direito. São Paulo: Cortez, 2011.

DAHLBERG, Gunilla; MOSS, Peter; PENCE, Alan. Qualidade na educação da primeira infância: perspectivas pós-modernas. Porto Alegre: Artmed, 2003.

LÜCK, Heloísa. Dimensões de gestão escolar e suas competências. Curitiba: Positivo, 2009.

CAMPOS, Maria. Malta; ROSEMBERG, Fúlvia. Critérios para um atendimento em creches que respeite os direitos fundamentais das crianças. Brasília: MEC/SEB, 2009.

PRESIDÊNCIA DA REPÚBLICA. Lei de diretrizes e bases da educação nacional. Disponível em <http://www.planalto.gov.br/ccivil 03/Leis/L9394.htm> Acesso em $28 \mathrm{dez}$. 2015.

Andressa Wiedenhoft Marafiga é graduada em Pedagogia pela Universidade Federal de Santa Maria, especialista em Gestão Educacional e estudante do curso de Mestrado em Educação na mesma instituição. Professora de educação infantil no Colégio Marco Polo.

Endereço: Avenida Presidente Vargas, 1303/12 - 97015-511 - Santa Maria - RS Brasil.

E-mail: andressawm@yahoo.com.br.

Taciana Camera Segat é graduada em Pedagogia Matérias Pedagógicas do 2응 Grau - Educação Pré-Escolar Licenciatura Plena pela Universidade Federal de Santa Maria, é mestre em Educação pela Universidade Federal de Santa Maria e doutora em Educação pela Universidade Federal do Rio Grande do Sul. Atualmente é professora no Departamento de Metodologia do Ensino da Universidade Federal de Santa Maria, professora no Curso de Pedagogia EAD e coordenadora dos Estágios do Curso de Pedagogia EAD.

Endereço: Rua Diamante, 615 - 97110-764 - Santa Maria - RS - Brasil.

E-mail: tcamerasegat@gmail.com.

Recebido em 4 de agosto de 2016.

Aceito em 27 de outubro de 2016. 